\title{
Ascher syndrome
}

INSERM

\section{Source}

INSERM. (1999). Orphanet: an online rare disease and orphan drug data base. Ascher syndrome. ORPHA:1253

Ascher syndrome is a very rare syndrome characterized by a combination of blepharochalasis, double lip, and non-toxic thyroid enlargement (seen in 10-50\% of cases), although the occurrence of all three signs at presentation is uncommon. Hypertrophy of the mucosal zone of the lip with persistence of the horizontal sulcus between cutaneous and mucosal zones gives an appearance of double lip, with the upper lip being frequently involved. Blepharochalasis, or episodic edema of eyelid, appears around puberty, is present in $80 \%$ of cases, is usually bilateral, and can rarely lead to vision impairment and other ocular complications. Most cases are sporadic, but familial cases (with a possible autosomal dominant inheritance) have also been reported. 